\title{
Cytochalasin B-induced membrane vesicles convey angiogenic activity of parental cells
}

\author{
Marina O. Gomzikova ${ }^{1}$, Margarita N. Zhuravleva ${ }^{1}$, Regina R. Miftakhova ${ }^{1}$, Svetlana \\ S. Arkhipova ${ }^{1}$, Vladimir G. Evtugin ${ }^{1}$, Svetlana F. Khaiboullina ${ }^{1,2}$, Andrey P. Kiyasov ${ }^{1}$, \\ Jenny L. Persson ${ }^{3}$, Nigel P. Mongan ${ }^{4,5}$, Richard G. Pestell ${ }^{6,7}$ and Albert A. Rizvanov ${ }^{1}$ \\ ${ }^{1}$ Kazan Federal University, Kazan, 420008, Russia \\ ${ }^{2}$ Department of Microbiology and Immunology, University of Nevada, Reno, Nevada, 89557, USA \\ ${ }^{3}$ Department of Translational Medicine, Lund University, 20502 Malmö, and Department of Molecular Biology, 90187 Umeå, \\ Umeå University \\ ${ }^{4}$ Cancer Biology and Translational Research, School of Veterinary Medicine and Science, University of Nottingham, LE12 5RD, UK \\ ${ }^{5}$ Department of Pharmacology, Weill Cornell Medicine, 1300 York Ave., New York, NY, 10065, USA \\ ${ }^{6}$ Pennsylvania Cancer and Regenerative Medicine Research Center, Baruch S. Blumberg Institute, Pennsylvania Biotechnology \\ Center, 100 East Lancaster Avenue, Suite, 222, Wynnewood, PA 19096. USA \\ ${ }^{7}$ Lee Kong Chian School of Medicine, Nanyang Technological University, Singapore 637551, Singapore \\ Correspondence to: Albert Rizvanov, email: Albert.Rizvanov@kpfu.ru \\ Keywords: extracellular vesicles, membrane vesicles, cytochalasin B-induced membrane vesicles, angiogenesis, cell-free therapy \\ Received: March 15, 2017 \\ Accepted: June 17, 2017 \\ Published: July 31, 2017
}

Copyright: Gomzikova et al. This is an open-access article distributed under the terms of the Creative Commons Attribution License 3.0 (CC BY 3.0), which permits unrestricted use, distribution, and reproduction in any medium, provided the original author and source are credited.

\section{ABSTRACT}

Naturally occurring extracellular vesicles (EVs) play essential roles in intracellular communication and delivery of bioactive molecules. Therefore it has been suggested that EVs could be used for delivery of therapeutics. However, to date the therapeutic application of EVs has been limited by number of factors, including limited yield and full understanding of their biological activities. To address these issues, we analyzed the morphology, molecular composition, fusion capacity and biological activity of Cytochalasin B-induced membrane vesicles (CIMVs). The size of these vesicles was comparable to that of naturally occurring EVs. In addition, we have shown that CIMVs from human SH-SY5Y cells contain elevated levels of VEGF as compared to the parental cells, and stimulate angiogenesis in vitro and in vivo.

\section{INTRODUCTION}

Cell therapy has been proven as an effective method for injury treatment [1-4]. Although considerable advances were made, current understanding of the mechanisms of transplanted cell therapeutic effects is incomplete. It is known that the tissue repair achieved is independent of transplanted cell-engraftment [5-6] and it can be achieved by injection of conditioned media derived from stem cell cultures [7-8] suggesting the therapeutic effect is paracrine and associated with the release of soluble factors. According to the paracrine hypothesis, transplanted cells secrete biologically active factors including cytokines and growth factors into extracellular space activating resident cells and supporting tissue growth and repair
[9-10]. More recent evidence also supports a paracrine role for extracellular vesicles (EVs) [11]. EV are important vehicles carrying proteins, mRNA, miRNAs and siRNA and provide a mechanism for cell crosstalk within tissues. Therefore, EVs could have great therapeutic potential as vehicles to deliver biologically active molecules. The therapeutic capacity of EVs was shown using models of a kidney injury [12], heart [13-14], liver [15] and nervous tissue injury [16].

In the last decade, technological advances have improved the yield and quality of isolated EVs [17-19]. Pick and colleagues [20] demonstrated that active agitation of Cytochalasin B-treated cells stimulated the production of membrane vesicles [20]. The membrane vesicles produced in this way retain normal cellular 
signaling capacities [20]. Mao and colleagues used the Cytochalasin B induced membrane vesicles as vectors for drug and nanoparticles delivery [21]. However the biological activities of membrane vesicles obtained from Cytochalasin B-treated cells have not been evaluated.

In this study, human neuroblastoma SH-SY5Y cells [22] were chosen as a source of CIMV due to their well-established angiogenic properties. It is known that neuroblastoma is a highly vascular solid tumor [23]. Previously we have shown that SH-SY5Y cells induce formation of capillary-like structures by human mesenchymal stem cells [24]. Therefore, in the current study we sought to determine whether Cytochalasin $B$ induced membrane vesicles (CIMVs) derived from SH-SY5Y bone marrow neuroblastoma cells could promote angiogenesis. To this end we examined the morphology, molecular composition, fusion capacity and biological activity of membrane vesicles generated from Cytochalasin B-treated SH-SY5Y cells. We have found that CIMVs maintain angiogenic properties of the parental cells in vitro and in vivo.

\section{RESULTS}

\section{Characterization of CIMVs}

Cytochalasin B targets actin cytoskeleton [25], therefore we first sought to determine the effect of Cytochalasin B treatment on actin fibers in SH-SY5Y cells as well as in CIMVs. Continuous actin microfilaments are found in untreated control SH-SY5Y cells (Figure 1). In contrast, in Cytochalasin B-treated SH-SY5Y cells actin microfilaments were disrupted and appeared as a submembrane "islands" (Figure 1). Confocal microscopy revealed actin cytoskeleton fragments in CIMVs (Figure 1).

Next, we investigated the structure and size of SHSY5Y derived CIMVs using transmission and scanning electron microscopy. We found that CIMVs had a roundshaped structure with a diameter varying from 80 to 1790 $\mathrm{nm}$. It should be noted that the majority of CIMVs (96\%) had a diameter of 100-1000 nm (Figure 2C) which is within the range of naturally occurring EVs.

\section{Interaction of CIMVs with recipient SH-SY5Y cells}

The cytoplasmic membrane of CIMVs and recipient SH-SY5Y cells were differentially labeled with DiD (red fluorescent dye) and $\mathrm{DiO}$ (green fluorescent dye), respectively. $\mathrm{DiD}$ and $\mathrm{DiO}$ dyes have non-overlapping excitation/emission spectrum (DiD - 644/665 nm; DiO $-484 / 501 \mathrm{~nm}$ ) and do not transfer between cytoplasmic membranes of neighboring cells [26]. CIMVs were incubated with the recipient SH-SY5Y cells and the surface and inner content of recipient SH-SY5Y cells were analyzed to determine the presence of the CIMVs membrane component. FACS analysis revealed that the majority of cells (95.88\%) had DiO and DiD dual fluorescence (Figure 3G). Round structures with red fluorescence (DiD positive) were detected on SH-SY5Y surface (Figure 3A-3C). Round structures with dual red and green fluorescence were detected within the cytoplasm of recipient SH-SY5Y (Figure 3D-3F, 3H). This data suggests that CIMVs merge with SH-SY5Y membranes and engage in the endosome trafficking pathway (Figure 3G).

\section{CIMVs exhibit angiogenic activity in vitro}

Previously we have shown that SH-SY5Y cells stimulate mesenchymal stem cell (MSC) formation of capillary-like tubes in matrigel [24]. Therefore we sought to compare whether SH-SY5Y derived CIMVs retain this pro-angiogenic property of the parental SHSY5Y cells. SH-SY5Y cells were mitotically inactivated using mitomycin $\mathrm{C}$ to eliminate the changes in secreted growth factors concentration introduced by active cell proliferation.

HUVECs capillary-like tube formation in matrigel was examined in vitro to determine the pro-angiogenic properties of CIMVs. HUVECs were pre-stained with CFDA-SE (eBioscience, USA) and co-cultured with CIMVs or mitotically inactivated SH-SY5Y cells for 16 hours before analysis of the capillary-like network (Figure 4A). The mean number of HUVECs capillarylike network branch points was calculated using Image J software. The mean number of capillary-like network branch points in the negative control group (HUVECs cultured in MCDB131 medium with $1 \%$ FBS) was $5.3 \pm 3.8$ (Figure 4B). As expected, HUVECs cultured with SH-SY5Y cells showed a significantly increased number of capillary-like structures $(43.5 \pm 3.5 ; \mathrm{p}<0.01)$ as compared to negative control. Furthermore, coculture of HUVECs with mitotically inactivated SHSY5Y cells also induced a significantly increased number of capillary-like structures $(34.7 \pm 1.15 ; \mathrm{p}<0.01)$. Consistent with our hypothesis that CIMVs retain the pro-angiogenic activity of the parental SH-SY5Y cells, CIMVs were shown to also induced a significant increase in capillary-like structures as compared to the negative control group $(41.3 \pm 8.5 ; \mathrm{p}<0.01)$ (Figure 4B). Indeed, under the conditions employed we found that CIMVs induced comparable HUVECs capillary-like structures as achieved by mitotically competent SH-SY5Y in vitro. Furthermore, CIMV induced angiogenesis was not associated with changes in HUVECs viability (Figure 3, Supplementary Data).

Endothelial cell proliferation is regulated primarily by ligands for receptor tyrosine kinases (RTKs) [23]. Therefore we sought to determine whether the angiogenic activity of CIMVs is associated with VEGF. We found $\sim 1.5$ fold higher level of VEGF in SH-SY5Y-derived CIMVs as compared to SH-SY5Y cells (Figure 4C). 


\section{CIMVs stimulate angiogenesis in vivo}

Given the increased capillary-like structure formation by HUVECs incubated with CIMVs in vitro, we next examined the pro-angiogenesis activity of CIMV in vivo using the matrigel plug angiogenesis assay in rat model. CIMVs and cells were first stained with $\mathrm{DiO}$, then matrigel solutions $(200 \mu \mathrm{l})$ containing either CIMVs or native or mitotically inactivated SH-SY5Y cells were prepared and injected subcutaneously into rat abdominal
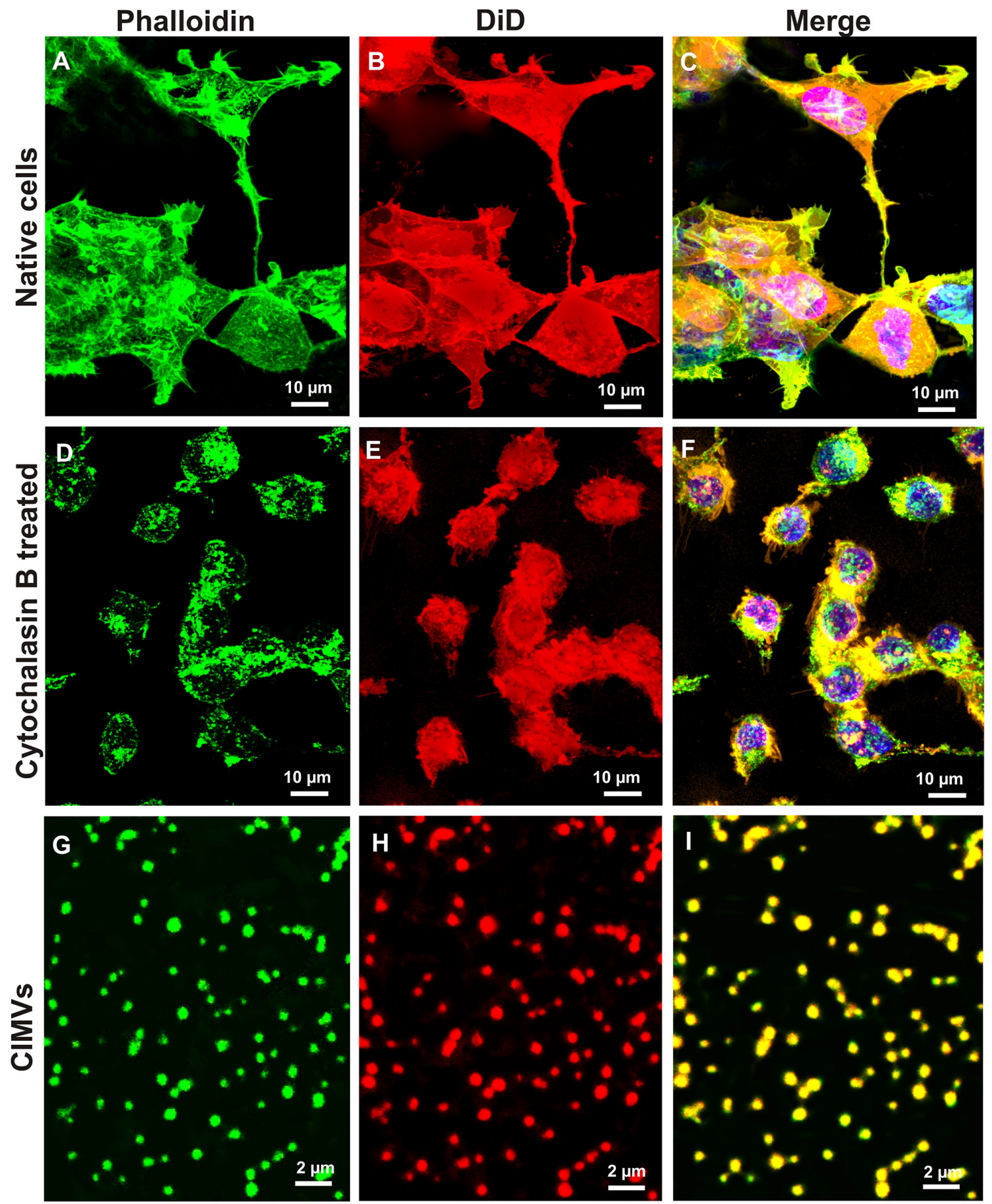

Figure 1: Comparison of the actin cytoskeleton structure in native and cytochalasin B treated cells and presence of actin filaments in CIMVs. SH-SY5Y cells were pre-stained with the cytoplasmic membrane dye DiD, then native cell (A-C), cells after 30 min incubation with cytochalasin B (D-F), or CIMVs (G-I) were fixed and stained with Phalloidin-Alexa488. Micrographs indicate that cytochalasin B induces actin cytoskeleton disorganization and as a consequence the loss of cells form. The actin cytoskeleton fragments which were formed under the effect of cytochalasin B are part of the CIMVs (G-I). 
flanks. Histological examination of matrigel implants was conducted 8 days later. Native, mitotically inactivated SH-SY5Y cells and CIMVs were detected by confocal microscopy in the matrigel implants 8 days after injection (Figure 5D, 5F, 5H). Also, newly developed blood capillaries were observed in matrigel containing native, mitotically inactivated SH-SY5Y cells and CIMVs (Figure $5 \mathrm{C}, 5 \mathrm{E}, 5 \mathrm{G})$. The number of blood vessels in control matrigel (without cells or CIMVs) was $0.065 \pm 0.04 \mathrm{cap} /$ $\mathrm{mm}^{2}$. More blood vessels were found in matrigel containing native SH-SY5Y cells, with an average capillary density 23fold higher $\left(1.5 \pm 0.23 \mathrm{cap} / \mathrm{mm}^{2} ; \mathrm{p}<0.01\right)$ than that in control (Figure 5I). Similar to native cells, the number of the new capillaries was 16.6 fold higher in matrigel containing mitotically inactivated SH-SY5Y cells $\left(1.08 \pm 0.1 \mathrm{cap} / \mathrm{mm}^{2}\right.$; $\mathrm{p}<0.01)$ than that in control. Finally, matrigel implants containing CIMVs achieved 12.7 fold more capillary density $\left(0.83 \pm 0.02 \mathrm{cap} / \mathrm{mm}^{2} ; \mathrm{p}<0.01\right)$ as compared to untreated control. We conclude that the SH-SY5Y derived CIMVs retain the pro-angiogenic properties of the parental
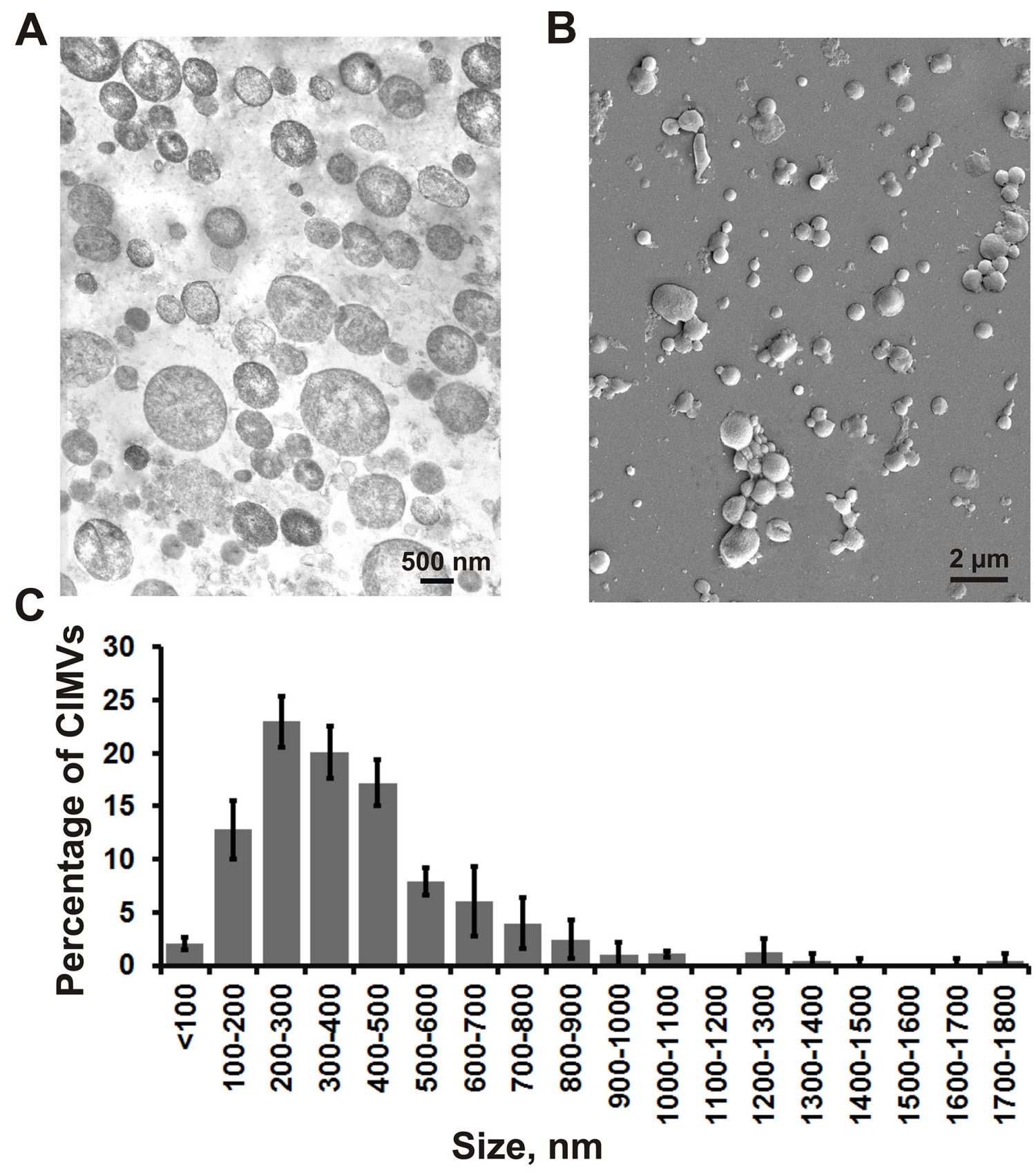

Figure 2: The structure, morphology and size distribution of CIMVs. Transmission electron microscopy (A) and scanning electron microscopy (B) was used to analyze the biophysical properties of SH-SY5Y properties of CIMVs. (C) Size distribution of CIMVs SH-SY5Y. For statistical analysis, at least six electron microscope images were analyzed from three independent experiments. 
cells. Interestingly, the angiogenic property of CIMVs was lower than that of SH-SY5Y parental cells, but closely resembling that of mitotically inactive cells. Although this may indicate that SH-SY5Y retains additional pro- angiogenic activity as compared to CIMVs, CIMVs also induced a statistically significant increase in angiogenesis as compared to control. As outlined later, the therapeutic use of CIMVs, but not native cells, is mechanistically feasible.
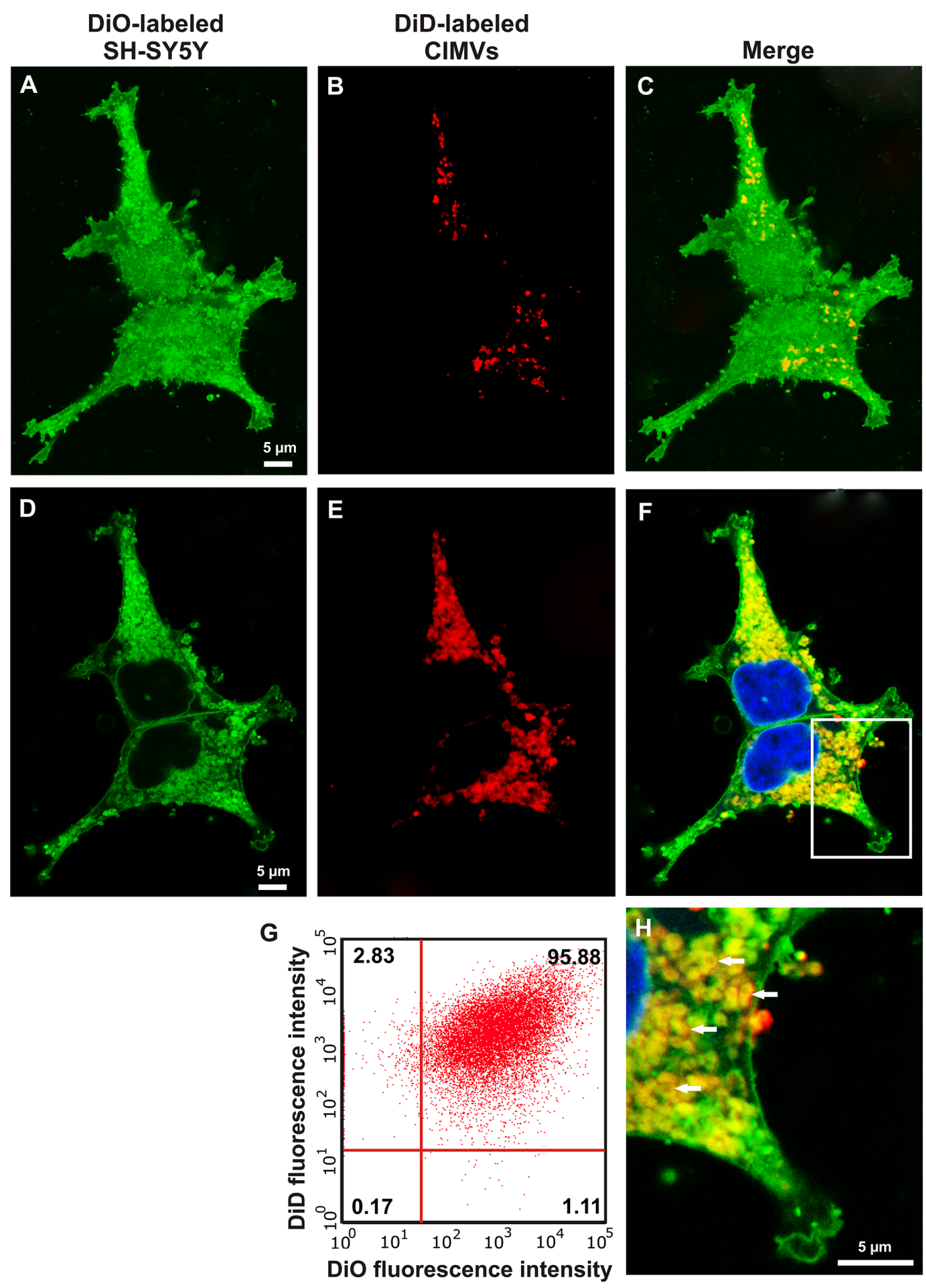

Figure 3: Interaction of CIMVs with recipient cells. Fluorescent microscopy Z-stack (A-F,H) and flow cytometry analysis (G) of SH-SY5Y recipient cells $24 \mathrm{~h}$ after $10 \mu \mathrm{g} / \mathrm{ml}$ CIMVs application were carried out. Recipient cells were pre-labeled with DiO cytoplasmic membrane dye and CIMVs were pre-labeled with DiD dye. Cells surface (A-C) and cells inner content (D-F,H) were analyzed for the presence of CIMVs membrane component. 


\section{DISCUSSION}

EVs are important vehicles carrying biologically active molecules providing cell cross talk within the tissue [27]. Recently there has been significant interest in the potential application of EVs as tools for cell-free delivery of therapeutics as unlike parental cells, it is believed there is no risk of tumor formation [28]. However, to date the yield of the naturally occurring EVs has been too low and is insufficient for therapeutic applications. Therefore, the development of new
A

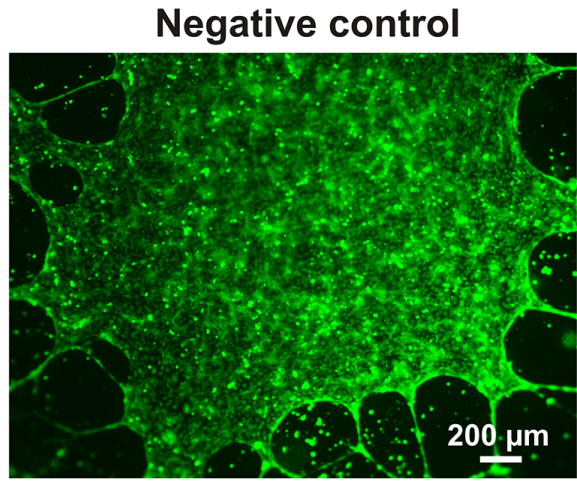

HUVEC + Mitomycin C treated SH-SY5Y

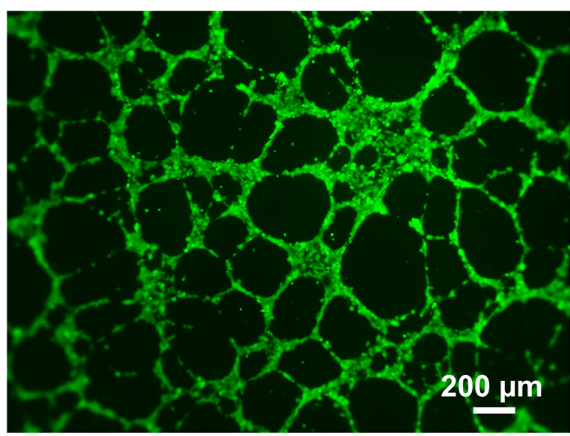

B

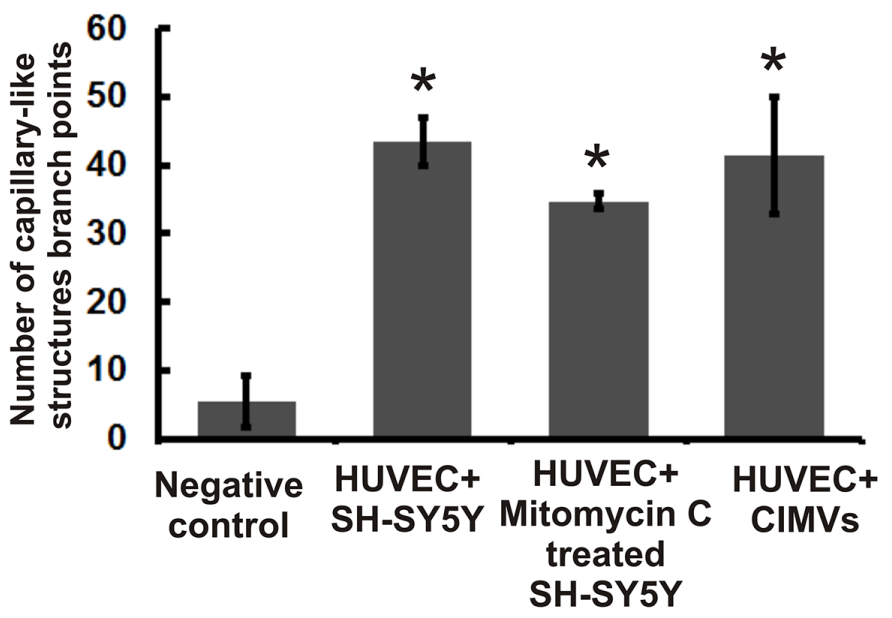

HUVEC + SH-SY5Y

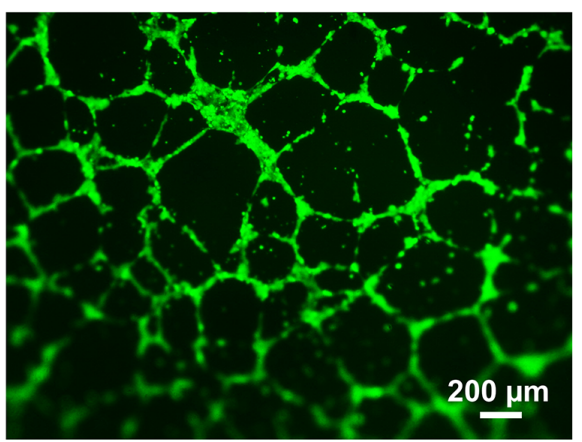

HUVEC + CIMVs

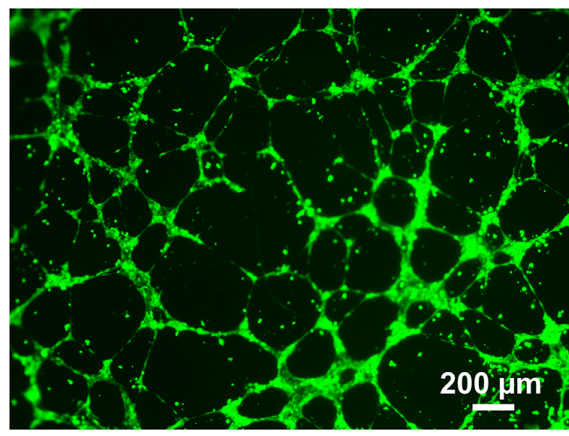

C

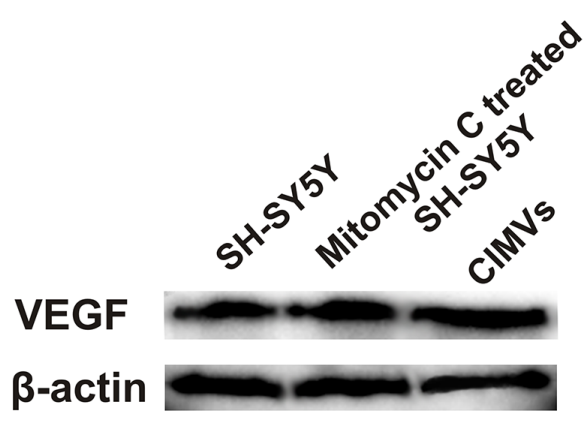

Figure 4: Evaluation of in vitro pro-angiogenic potential of mitotically inactivated cells and CIMVs SH-SY5Y. (A) Fluorescence micrographs of HUVEC culture after 16 hours of incubation with native/ mitotically inactivated SH-SY5Y cells or CIMVs. (B) Quantitation of the capillary-like structure branch points number formed by HUVECs after 16 hours of co-culture with native/ mitotically inactivated SH-SY5Y cells or CIMVs. The data represents mean \{plus minus\} SD. For statistical analysis six well of 96-well plate were analyzed per experimental group. (C) Representative western blots showing VEGF and $\beta$-actin in native/ mitotically inactivated SH-SY5Y cells or CIMVs. 

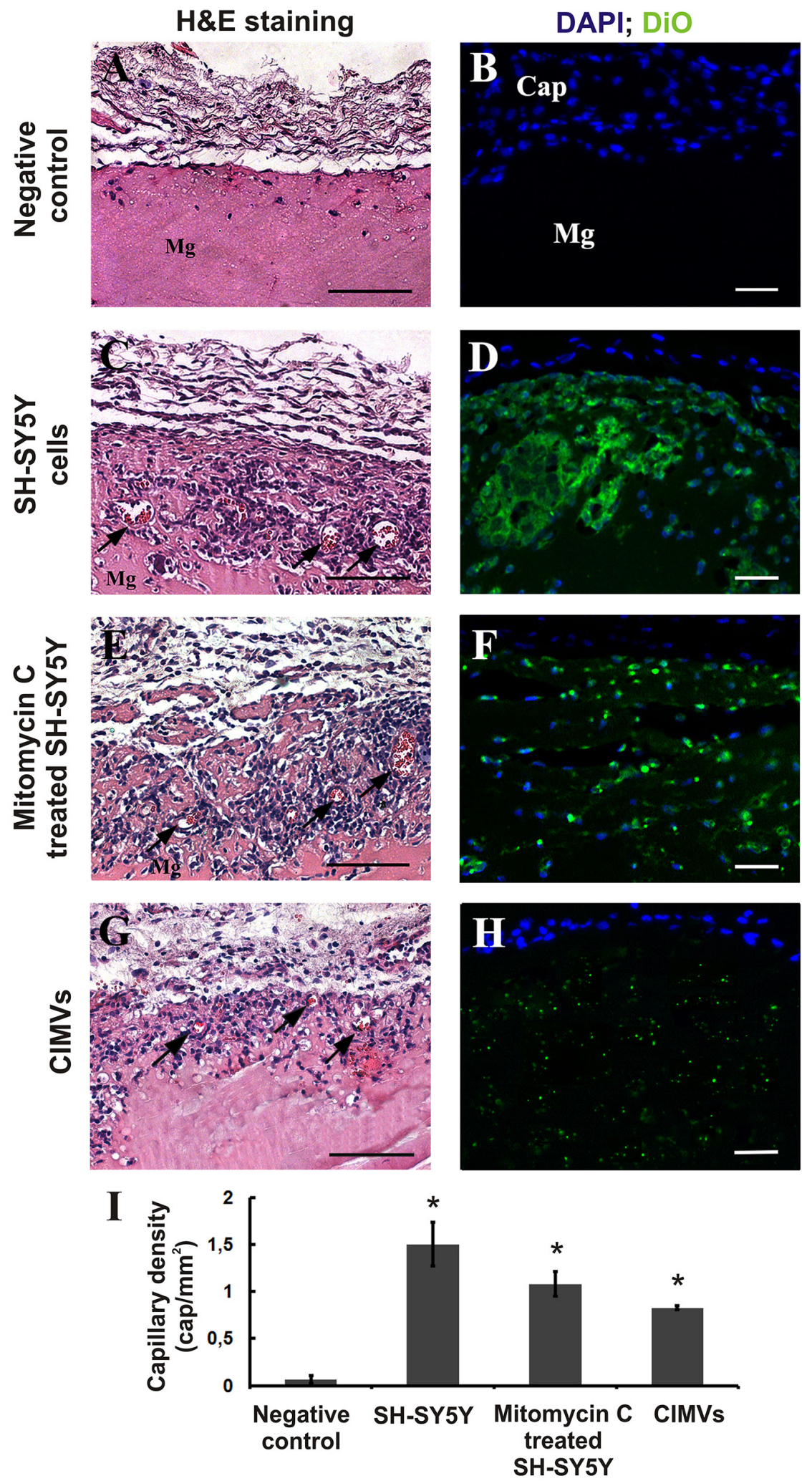

Figure 5: CIMVs stimulate angiogenesis in vivo. Representative images of control matrigel plugs $(\mathbf{A}, \mathbf{B})$, matrigel plugs with native (C, D), mitotically inactivated (E, F) SH-SY5Y cells or CIMVs $(\mathbf{G}, \mathbf{H}) 8$ days after subcutaneous injection in Rattus norvegicus (6 animals per experimental group). Hematoxylin/eosin staining and fluorescence micrographs are shown. $\mathrm{Mg}$ - Matrigel, Cap - fibrous capsule. Arrows mark the position of the sprouting blood capillaries. (I) Quantitation of the capillary density in matrigel plugs. The data represents mean \{plus minus\} SD. For statistical analysis, fifteen hematoxylin and eosin stained slides per animal were analyzed. 
methods to generate EVs has been an area of active research. The use of cytochalasin B is now a well-established approach to generate sufficient quantities of membrane vesicles for therapeutic development [20]. However, it remained unclear whether CIMVs retain cell regulatory capacity similar to those of naturally occurring EVs.

Studies of the molecular mechanisms regulating extracellular vesicles formation, revealed that budding of microvesicles requires local actin cytoskeleton disorganization by the $\mathrm{Ca}^{2+}$-dependent protease, calpain, where digested actin microfilament fragments become captured within the microvesicles [29-30]. Since cytochalasin B mechanisms of action are similar to those of calpain, the presence of actin microfilaments within the CIMVs was investigated. Here we found that actin molecules are captured in CIMVs. Furthermore, we show that CMIVs were $\sim 100-1000 \mathrm{~nm}$ in diameter, which is comparable with naturally occurring EVs [31-35].

Naturally occurring EVs can acquire and transport biologically active molecules. Also, EVs are able to fuse directly with the cytoplasmic membrane of recipient cells and be captured by endocytosis [36]. However whether the membrane fusion capacity and mechanisms of intracellular transport were retained by CIMVs was unknown. Here for the first time we have shown that CIMVs can fuse with the recipient cell membrane. Also, we found that CIMVs, like naturally occurring EVs, can be transported via endocytosis. This data suggests that CIMVs may have similar bio-physical properties, closely resembling that of natural microvesicles, and thus are likely suitable as vectors for delivery of bioactive molecules.

Naturally occurring EVs can deliver biologically active substances to recipient cells, and thereby regulate cell growth and proliferation [37-38]. Therefore, we investigated the effect of CIMVs on HUVECs capillarylike structures formation in vitro. Our data, for the first time indicates that CIMVs can induce the angiogenesis, similar to that previously described for the parental cells [24]. We believe that VEGF could, in part, explain the proangiogenic properties of CIMVs.

The pro-angiogenic potential of the SH-SY5Y neuroblastoma cells derived CIMVs was also confirmed using an in vivo model. Tumor cells secrete various cytokines and chemokines attracting endothelial cells [39] and thereby stimulate angiogenesis. Subcutaneously injected in matrigel cells or CIMVs of SH-SY5Y induced the blood capillary sprouting by activation proinflammatory and pro-angiogenic pathways [39]. Although the angiogenic activity of native SH-SY5Y cells was 1.8 times higher than CIMVs, it was still comparable to that of mitotically inactive cells. We believe that the high angiogenic activity of SH-SY5Y cells was due to the ability of these cells to proliferate, thus continuously increasing the number of tumor cells releasing growth factors. On the contrary, CIMVs and mitomycin C treated cells fail to proliferate, thus although they able to secrete bioactive molecules, the amount of cytokines produced remains unchanged. The potential clinical advantages of this feature of CIMVs in terms of controlling therapeutic concentrations and minimizing off-target effects are clear.

In conclusion, we demonstrated that cytochalasin B-induced SH-SY5Y-derived membrane vesicles retain the properties of the donor cells, as they can stimulate angiogenesis in vitro and in vivo. Unlike the naturally occurring EVs, CIMVs can be produced in large quantity and be scaled to an industrial production level. This makes the CIMVs derived from primary cells (mesenchymal stem cells, endothelial cells, endothelial progenitor cells etc.) an attractive therapeutic approach to trigger the angiogenesis in clinical case of limb ischemia, diabetescaused ischemic cardiovascular disease, ischemic stroke, myocardial infarction [40-42]. We propose that the CIMVs may serve as a tool for cell-free therapeutic biomolecules delivery.

\section{MATERIALS AND METHODS}

\section{Cell culture}

SH-SY5Y cells (ATCC® CRL-2266, American Type Culture Collection, Manassas, VA) were maintained in Dulbecco's modified Eagle's medium (DMEM; PanEco, Russia) with 10\% fetal bovine serum (FBS; GE Healthcare, USA) and 2mM L-glutamine (PanEco, Russia) at $37^{\circ} \mathrm{C}$ with $5 \% \mathrm{CO}_{2}$. Human umbilical vein endothelial cells (HUVECs) were isolated as described previously [43]. Experiments using human samples were reviewed and approved by the local Ethical Committee of Kazan (Volga region) Federal University based on article 20 of the Federal Legislation on "Health Protection of Citizens of the Russian Federation” № 323-FL, 21.11.2011. Informed consent was obtained from all patients for the use of specimens in research and the Helsinki Declaration observed. Briefly, the umbilical cord was washed with Hanks' solution (PanEco, Russia) containing 100 I.U./mL penicillin, $100 \mu \mathrm{g} / \mathrm{mL}$ streptomycin (PanEco, Russia). Then, $1 \mathrm{~cm}$ of tissue was removed from each end of the cord. A catheter (Apexmed International, Netherlands) was inserted into the umbilical vein, the vein perfused with Hanks' solution containing antibiotics. Umbilical vein endothelial cells were then dissociated by incubating with trypsin-EDTA $(0.25 \%)$ solution (Life Technologies, USA) for 20 minutes at $37^{\circ} \mathrm{C}$. Cells were retrieved by centrifugation (1500 rpm for $10 \mathrm{~min}$ ), resuspended in HUVEC culture medium and incubated at $37^{\circ} \mathrm{C}$ in a humidified atmosphere containing 5\% $\mathrm{CO}_{2}$. HUVECs phenotype was confirmed by flow cytometry $\left(\mathrm{CD} 31^{+}\right.$, $\left.\mathrm{CD}^{105^{+}}, \mathrm{CD}_{146}+\mathrm{CD}^{4} 4^{+}, \mathrm{CD} 45^{-}, \mathrm{CD} 14-\right)$. HUVECs were maintained in MCDB131 medium (Sigma-Aldrich, USA) with $20 \%$ FBS (GE Healthcare, USA) supplemented with non-essential amino acids (Life Technologies, USA), $10 \mathrm{ng} / \mathrm{ml}$ FGF2 (Sigma-Aldrich, USA), 10 ng/ml VEGF 
(Sigma-Aldrich, USA), $10 \mathrm{ng} / \mathrm{ml}$ insulin-like growth factor (Sigma-Aldrich, USA), $50 \mathrm{ng} / \mathrm{ml}$ endothelial cell growth supplement (Sigma-Aldrich, USA) and $10 \mathrm{ug} / \mathrm{ml}$ heparin (Sigma-Aldrich, USA).

\section{CIMVs production}

CIMVs were prepared as described by Pick et al. [20], with modifications. Briefly, SH-SY5Y cells were washed twice with PBS, and incubated in DMEM containing $10 \mu \mathrm{g} / \mathrm{ml}$ of Cytochalasin B (Sigma-Aldrich, USA) for $30 \mathrm{~min}\left(37^{\circ} \mathrm{C}, 5 \% \mathrm{CO}_{2}\right)$. At the end of incubation, the cell suspension was vortexed vigorously for $30 \mathrm{sec}$ and pelleted (100 $\mathrm{g}$ for $10 \mathrm{~min}$ ). The supernatant was subject to two subsequent centrifugation steps (100 $\mathrm{g}$ for $20 \mathrm{~min}$ and $2000 \mathrm{~g}$ for $25 \mathrm{~min}$ ). The resulting pellet contained CIMVs.

\section{Actin microfilaments and cytoplasmic membrane staining}

SH-SY5Y cells and CIMVs were fixed (10\% formalin for $15 \mathrm{~min}$ ), washed twice with PBS and permeabilized using $0.1 \%$ Tween 20 for 15 min. Phalloidin conjugated with Alexa 488 (SantaCruz, USA) was added for $15 \mathrm{~min}$ to visualize actin. Nuclei were stained with Hoechst 33342 (SantaCruz, USA) for $10 \mathrm{~min}$. Lipophilic dyes DiD and DiO (Life Technologies, USA) were used to visualize cell membranes. Cell suspension $\left(1 \times 10^{6} \mathrm{cells} / \mathrm{ml}\right)$ was incubated with $5 \mu \mathrm{M}$ of $\mathrm{DiO}$ or DiD dyes for $15 \mathrm{~min}$ $\left(37^{\circ} \mathrm{C}, 5 \% \mathrm{CO}_{2}\right)$ and washed (3x) with complete medium (DMEM with 10\% FBS, 2mM L-glutamine). Cells were analyzed by confocal laser scanning microscopy (Carl Zeiss LSM 780, Germany) and flow cytometry (BD FACS Aria III, USA).

\section{Mitotic inactivation of SH-SY5Y cells}

SH-SY5Y cells were treated with $10 \mu \mathrm{g} / \mathrm{ml}$ mitomycin $\mathrm{C}$ (Sigma, USA) for $1-4$ hours $\left(37^{\circ} \mathrm{C}, 5 \% \mathrm{CO}_{2}\right)$. Cells were washed (PBS, 3 times) and cultured in a complete culture media (DMEM with 10\% FBS, 2mM L-glutamine). Cell proliferation was accessed using xCELLigence Real-Time Cell Analyzer (ACEA BIO, USA).

\section{Western blot analysis}

SH-SY5Y cells and CIMVs were lysed in a RIPA lysis buffer $(50 \mathrm{mM}$ Tris- $\mathrm{HCl} \mathrm{pH} 7.4,1 \%$ Triton X-100, $0.5 \%$ Na-deoxycholate, $0.1 \%$ SDS, $150 \mathrm{mM} \mathrm{NaCl}$, 2mM EDTA, 1mM PMSF). Protein concentration was determined by bicinchoninic acid (BCA) protein assay (Thermo Scientific, USA). Samples ( $40 \mu \mathrm{g}$ ) were separated in $12 \%$ SDS-PAGE under denaturing conditions and then transferred to polyvinylidene fluoride (PVDF) membrane. The membrane was blocked in 5\% non-fat dry milkcontaining PBS-T (PBS $+0,1 \%$ Tween) solution. Proteins were probed using primary antibodies against VEGF (1:1000; SantaCruz Biotech, USA) and $\beta$-actin (1:100; GenScript, USA) followed by secondary antibodies (1:5000; GenScript, USA) conjugated with horseradish peroxidase. Protein bands were visualized by ECL reagent (Reagent A: $1.25 \mathrm{mM}$ Luminol in $0.1 \mathrm{M}$ Tris- $\mathrm{HCl} \mathrm{pH} \mathrm{8.5;}$ reagent B: $68 \mathrm{mM}$ p-Coumaric acid in DMSO; reagent C: $30 \%$ hydrogen peroxide) and detected on a ChemiDoc Imaging System by Image Lab software (Bio-Rad, USA). Densitometric analysis, relative to total protein, was performed using Image $\mathbf{J}$ software.

\section{Transmission and scanning electron microscopy}

CIMVs were fixed (2.5\% glutaraldehyde, 24 hours) and incubated in $1 \%$ osmium tetroxide for 1 hour. CIMVs were dehydrated using graded ethanol series, followed by acetone, oxypropylene and epoxy resin embedment. The ultrathin sections were cut using Leica EM ultramicrotome (Leica, USA), mounted on copper grid (Sigma, USA) and contrasted with uranyl acetate and lead citrate (Himmed, Russia). Sections were examined using Jeol SX 1200 electron microscope (Jeol, Japan). For SEM, CIMVs were fixed ( $10 \%$ formalin for $15 \mathrm{~min})$, dehydrated using graded alcohol series and dried at $37^{\circ} \mathrm{C}$. Prior to imaging, samples were sputter coated with gold/palladium in a Quorum T150ES sputter coater (Quorum Technologies Ltd, United Kingdom). Slides were analyzed using Merlin (CarlZeiss, Germany) field emission scanning electron microscope. For size determination, CIMVs were obtained in three independent experiments and at least six electron microscope images were done in each experiment for subsequent statistical analysis.

\section{In vitro assessment of capillary-like structure formation by HUVECs}

HUVECs $\left(2 \times 10^{4}\right.$ cells $)$ were seeded in tissue culture wells pre-coated with Matrigel Growth Factor Reduced Basement Membrane Matrix (Becton Dickinson, USA). CIMVs were added to the HUVECs monolayer at a concentration equivalent to $2 \times 10^{4} \mathrm{SH}-\mathrm{SY} 5 \mathrm{Y}$ cells based on total protein concentration. HUVECs maintained in MCDB131 media supplemented with 1\% FBS was used as a negative control. HUVECs and CIMVs were incubated for 16 hours $\left(37^{\circ} \mathrm{C}, 5 \% \mathrm{CO}_{2}\right)$ and used to analyze by AxioOberver.Z1 fluorescence microscope (CarlZeiss, Germany). Six replicates were analyzed per experimental group for statistical analyses.

\section{In vivo assessment of pro-angiogenic activity of SH-SY5Y and derived CIMVs}

The animal study was approved by KFU ethics committee (protocol \#2, date 05.05.2015) according with the rules adopted in KFU and Russian Federal 
Laws. Angiogenic activity was examined using Wistar rats (Pushchino Laboratory, Russia) with 6 animals per experimental group. Matrigel $(200 \mu \mathrm{l})$ containing $2 \times 10^{6}$ SH-SY5Y cells (Group 1), 2x106 mitotically inactivated SHSY5Y cells (Group 2), SH-SY5Y-derived CIMVs at a concentration equivalent to $2 \times 10^{6} \mathrm{SH}-\mathrm{SY} 5 \mathrm{Y}$ cells based on total protein concentration $(4 \mathrm{mg} / \mathrm{ml}$ of total protein) (Group 3) and PBS (Group 4) was injected subcutaneously in the abdominal flanks. SH-SY5 cells and CIMVs were pre-labeled with the membrane dye DiO (Life Technologies, USA). Eight days after injection animals were sacrificed and matrigel plugs collected for examination. Matrigel plugs were frozen in liquid nitrogen and used to make $6 \mu \mathrm{m}$ sections (NM560CryoStar, Thermo Scientific, USA) for immunofluorescent analysis. Also, matrigel plug were paraffin embedded and stained with hematoxylin and eosin. Slides were examined using AxioOberver.Z1 (CarlZeiss, Germany) microscope with Axio Vision 4.8 software (CarlZeiss). For statistical analysis ten hematoxylin and eosin stained slides were analyzed per experimental group.

\section{Statistical analysis}

Statistical analysis was performed using Student's t-test (Graphpad Software, San Diego, CA) with significance level $\mathrm{p}<0.05$.

\section{CONFLICTS OF INTEREST}

The authors declare that there is no conflicts of interests regarding the publication of this article.

\section{GRANT SUPPORT}

The work is performed according to the Russian Government Program of Competitive Growth of Kazan Federal University and subsidy allocated to Kazan Federal University for the state assignment in the sphere of scientific activities. Some of the experiments were conducted using the equipment of Interdisciplinary center for collective use of Kazan Federal University supported by Ministry of Education of Russia, Interdisciplinary Center for Analytical Microscopy and Pharmaceutical Research and Education Center, Kazan (Volga Region) Federal University, Kazan, Russia. JLP was supported by the Swedish Cancer Foundation, Lund University and the Medical Faculty at Umeå University, Sweden. NPM was funded by the University of Nottingham. RAA was supported by state assignment 20.5175.2017/6.7 of the Ministry of Education and Science of Russian Federation.

\section{REFERENCES}

1. Battistella V, de Freitas GR, da Fonseca LM, Mercante D, Gutfilen B, Goldenberg RC, Dias JV, Kasai-Brunswick
TH, Wajnberg E, Rosado-de-Castro PH, Alves-Leon SV, Mendez-Otero R, Andre C. Safety of autologous bone marrow mononuclear cell transplantation in patients with nonacute ischemic stroke. Regen Med. 2011; 6: 45-52. https://doi.org/10.2217/rme.10.97.

2. Cox CS, Jr., Baumgartner JE, Harting MT, Worth LL, Walker PA, Shah SK, Ewing-Cobbs L, Hasan KM, Day MC, Lee D, Jimenez F, Gee A. Autologous bone marrow mononuclear cell therapy for severe traumatic brain injury in children. Neurosurgery. 2011; 68: 588-600. https://doi. org/10.1227/NEU.0b013e318207734c.

3. Osawa H, Orii K, Terunuma H, Abraham SJ. Combining autologous peripheral blood mononuclear cells with fibroblast growth factor therapy along with stringent infection control leading to successful limb salvage in diabetic patient with chronic renal failure and severe toe gangrene. Int J Stem Cells. 2014; 7: 158-61. https://doi. org/10.15283/ijsc.2014.7.2.158 ijsc_07_158 [pii].

4. Jungebluth P, Holzgraefe B, Lim ML, Duru AD, Lundin V, Heldring N, Wiklander OP, Nordin JZ, Chrobok M, Roderburg C, Sjoqvist S, Anderstam B, Beltran Rodriguez A, et al. Autologous Peripheral Blood Mononuclear Cells as Treatment in Refractory Acute Respiratory Distress Syndrome. Respiration. 2015; 90: 481-92. doi: 000441799 [pii] https://doi.org/10.1159/000441799.

5. Duffield JS, Park KM, Hsiao LL, Kelley VR, Scadden DT, Ichimura T, Bonventre JV. Restoration of tubular epithelial cells during repair of the postischemic kidney occurs independently of bone marrow-derived stem cells. J Clin Invest. 2005; 115: 1743-55. https://doi.org/10.1172/JCI22593.

6. Biancone L, Bruno S, Deregibus MC, Tetta C, Camussi G. Therapeutic potential of mesenchymal stem cell-derived microvesicles. Nephrol Dial Transplant. 2012; 27: 3037-42. doi: gfs168 [pii] https://doi.org/10.1093/ndt/gfs168.

7. Takahashi M, Li TS, Suzuki R, Kobayashi T, Ito H, Ikeda Y, Matsuzaki M, Hamano K. Cytokines produced by bone marrow cells can contribute to functional improvement of the infarcted heart by protecting cardiomyocytes from ischemic injury. Am J Physiol Heart Circ Physiol. 2006; 291: H886-93. doi: 00142.2006 [pii] https://doi. org/10.1152/ajpheart.00142.2006.

8. den Haan MC, Grauss RW, Smits AM, Winter EM, van Tuyn J, Pijnappels DA, Steendijk P, Gittenberger-De Groot AC, van der Laarse A, Fibbe WE, de Vries AA, Schalij MJ, Doevendans PA, et al. Cardiomyogenic differentiationindependent improvement of cardiac function by human cardiomyocyte progenitor cell injection in ischaemic mouse hearts. J Cell Mol Med. 2012; 16: 1508-21. https://doi. org/10.1111/j.1582-4934.2011.01468.x.

9. Gnecchi M, He H, Noiseux N, Liang OD, Zhang L, Morello F, Mu H, Melo LG, Pratt RE, Ingwall JS, Dzau VJ. Evidence supporting paracrine hypothesis for Akt-modified mesenchymal stem cell-mediated cardiac protection and functional improvement. FASEB J. 2006; 20: 661-9. doi: 20/6/661 [pii] https://doi.org/10.1096/fj.05-5211com. 
10. Mirotsou M, Jayawardena TM, Schmeckpeper J, Gnecchi M, Dzau VJ. Paracrine mechanisms of stem cell reparative and regenerative actions in the heart. J Mol Cell Cardiol. 2011; 50: 280-9. doi: S0022-2828(10)00292-0 [pii] https:// doi.org/10.1016/j.yjmcc.2010.08.005.

11. De Jong OG, Van Balkom BW, Schiffelers RM, Bouten $\mathrm{CV}$, Verhaar MC. Extracellular vesicles: potential roles in regenerative medicine. Front Immunol. 2014; 5: 608. https://doi.org/10.3389/fimmu.2014.00608.

12. Bruno S, Grange C, Deregibus MC, Calogero RA, Saviozzi S, Collino F, Morando L, Busca A, Falda M, Bussolati B, Tetta C, Camussi G. Mesenchymal stem cell-derived microvesicles protect against acute tubular injury. J Am Soc Nephrol. 2009; 20: 1053-67. doi: ASN.2008070798 [pii] https://doi.org/10.1681/ASN.2008070798.

13. Lai RC, Arslan F, Lee MM, Sze NS, Choo A, Chen TS, Salto-Tellez M, Timmers L, Lee CN, El Oakley RM, Pasterkamp G, de Kleijn DP, Lim SK. Exosome secreted by MSC reduces myocardial ischemia/reperfusion injury. Stem Cell Res. 2010; 4: 214-22. doi: S1873-5061(09)00141-X [pii] https://doi.org/10.1016/j.scr.2009.12.003.

14. Arslan F, Lai RC, Smeets MB, Akeroyd L, Choo A, Aguor EN, Timmers L, van Rijen HV, Doevendans PA, Pasterkamp G, Lim SK, de Kleijn DP. Mesenchymal stem cell-derived exosomes increase ATP levels, decrease oxidative stress and activate PI3K/Akt pathway to enhance myocardial viability and prevent adverse remodeling after myocardial ischemia/ reperfusion injury. Stem Cell Res. 2013; 10: 301-12. doi: S18735061(13)00003-2 [pii] https://doi.org/10.1016/j.scr.2013.01.002.

15. Herrera MB, Fonsato V, Gatti S, Deregibus MC, Sordi A, Cantarella D, Calogero R, Bussolati B, Tetta C, Camussi G. Human liver stem cell-derived microvesicles accelerate hepatic regeneration in hepatectomized rats. J Cell Mol Med. 2010; 14: 1605-18. doi: JCMM860 [pii] https://doi. org/10.1111/j.1582-4934.2009.00860.x.

16. Xin H, Li Y, Cui Y, Yang JJ, Zhang ZG, Chopp M. Systemic administration of exosomes released from mesenchymal stromal cells promote functional recovery and neurovascular plasticity after stroke in rats. J Cereb Blood Flow Metab. 2013; 33: 1711-5. doi: jcbfm2013152 [pii] https://doi.org/10.1038/jcbfm.2013.152.

17. Raposo G, Nijman HW, Stoorvogel W, Liejendekker R, Harding CV, Melief CJ, Geuze HJ. B lymphocytes secrete antigen-presenting vesicles. J Exp Med. 1996; 183: 1161-72.

18. Clayton A, Court J, Navabi H, Adams M, Mason MD, Hobot JA, Newman GR, Jasani B. Analysis of antigen presenting cell derived exosomes, based on immunomagnetic isolation and flow cytometry. J Immunol Methods. 2001; 247: 163-74. doi: S0022-1759(00)00321-5 [pii].

19. Witwer KW, Buzas EI, Bemis LT, Bora A, Lasser C, Lotvall J, Nolte-'t Hoen EN, Piper MG, Sivaraman S, Skog J, Thery C, Wauben MH, Hochberg F. Standardization of sample collection, isolation and analysis methods in extracellular vesicle research. J Extracell Vesicles. 2013; 2. https://doi. org/10.3402/jev.v2i0.20360 20360 [pii].

20. Pick H, Schmid EL, Tairi AP, Ilegems E, Hovius R, Vogel $\mathrm{H}$. Investigating cellular signaling reactions in single attoliter vesicles. J Am Chem Soc. 2005; 127: 2908-12. https://doi.org/10.1021/ja044605x.

21. Mao Z, Cartier R, Hohl A, Farinacci M, Dorhoi A, Nguyen TL, Mulvaney P, Ralston J, Kaufmann SH, Mohwald H, Wang D. Cells as factories for humanized encapsulation. Nano Lett. 2011; 11: 2152-6. https://doi.org/10.1021/ n1200801n.

22. Biedler JL, Roffler-Tarlov S, Schachner M, Freedman LS. Multiple neurotransmitter synthesis by human neuroblastoma cell lines and clones. Cancer Res. 1978; 38 : 3751-7.

23. Roy Choudhury S, Karmakar S, Banik NL, Ray SK. Targeting angiogenesis for controlling neuroblastoma. J Oncol. 2012; 2012: 782020. https://doi. org/10.1155/2012/782020.

24. Rizvanov AA, Yalvac ME, Shafigullina AK, Salafutdinov, II, Blatt NL, Sahin F, Kiyasov AP, Palotas A. Interaction and self-organization of human mesenchymal stem cells and neuro-blastoma SH-SY5Y cells under co-culture conditions: A novel system for modeling cancer cell microenvironment. Eur J Pharm Biopharm. 2010; 76: 253-9. doi: S0939-6411(10)00148-7 [pii] https://doi.org/10.1016/j. ejpb.2010.05.012.

25. MacLean-Fletcher S, Pollard TD. Mechanism of action of cytochalasin B on actin. Cell. 1980; 20: 329-41. doi: 00928674(80)90619-4 [pii].

26. Honig MG, Hume RI. Fluorescent carbocyanine dyes allow living neurons of identified origin to be studied in long-term cultures. J Cell Biol. 1986; 103: 171-87.

27. Tetta C, Ghigo E, Silengo L, Deregibus MC, Camussi G. Extracellular vesicles as an emerging mechanism of cell-tocell communication. Endocrine. 2013; 44: 11-9. https://doi. org/10.1007/s12020-012-9839-0.

28. Gomzikova M.O. RAA. Current Trends in Regenerative Medicine: From Cell to Cell-Free Therapy. BioNanoScience. 2016: 1-6. https://doi.org/10.1007/ s12668-016-0348-0.

29. Antonyak MA, Li B, Boroughs LK, Johnson JL, Druso JE, Bryant KL, Holowka DA, Cerione RA. Cancer cell-derived microvesicles induce transformation by transferring tissue transglutaminase and fibronectin to recipient cells. Proc Natl Acad Sci U S A. 2011; 108: 4852-7. doi: 1017667108 [pii] https://doi.org/10.1073/pnas.1017667108.

30. Kawamoto T, Ohga N, Akiyama K, Hirata N, Kitahara S, Maishi N, Osawa T, Yamamoto K, Kondoh M, Shindoh M, Hida Y, Hida K. Tumor-derived microvesicles induce proangiogenic phenotype in endothelial cells via endocytosis. PLoS One. 2012; 7: e34045. https://doi. org/10.1371/journal.pone.0034045 PONE-D-11-21833 [pii]. 
31. Raposo G, Stoorvogel W. Extracellular vesicles: exosomes, microvesicles, and friends. J Cell Biol. 2013; 200: 373-83. doi: jcb.201211138 [pii] https://doi.org/10.1083/jcb.201211138.

32. Choi DS, Kim DK, Kim YK, Gho YS. Proteomics, transcriptomics and lipidomics of exosomes and ectosomes. Proteomics. 2013; 13: 1554-71. https://doi.org/10.1002/ pmic. 201200329.

33. Simpson RJ, Lim JW, Moritz RL, Mathivanan S. Exosomes: proteomic insights and diagnostic potential. Expert Rev Proteomics. 2009; 6: 267-83. https://doi.org/10.1586/ epr.09.17.

34. Ji H, Chen M, Greening DW, He W, Rai A, Zhang W, Simpson RJ. Deep sequencing of RNA from three different extracellular vesicle (EV) subtypes released from the human LIM1863 colon cancer cell line uncovers distinct miRNAenrichment signatures. PLoS One. 2014; 9: e110314. https:// doi.org/10.1371/journal.pone.0110314 PONE-D-14-23898 [pii].

35. Akers JC, Gonda D, Kim R, Carter BS, Chen CC. Biogenesis of extracellular vesicles (EV): exosomes, microvesicles, retrovirus-like vesicles, and apoptotic bodies. J Neurooncol. 2013; 113: 1-11. https://doi.org/10.1007/ s11060-013-1084-8.

36. Mulcahy LA, Pink RC, Carter DR. Routes and mechanisms of extracellular vesicle uptake. J Extracell Vesicles. 2014; 3. https://doi.org/10.3402/jev.v3.24641 24641 [pii].

37. de Vrij J, Maas SL, Kwappenberg KM, Schnoor R, Kleijn A, Dekker L, Luider TM, de Witte LD, Litjens M, van Strien ME, Hol EM, Kroonen J, Robe PA, et al. Glioblastomaderived extracellular vesicles modify the phenotype of monocytic cells. Int J Cancer. 2015; 137: 1630-42. https:// doi.org/10.1002/ijc.29521.

38. Giusti I, Delle Monache S, Di Francesco M, Sanita P, D’Ascenzo S, Gravina GL, Festuccia C, Dolo V. From glioblastoma to endothelial cells through extracellular vesicles: messages for angiogenesis. Tumour Biol. 2016; 37: 12743-53. https://doi.org/10.1007/s13277-016-5165-0 10.1007/s13277-016-5165-0 [pii].

39. Dieterich L. (2011). Molecular regulation of inflammation and angiogenesis in the tumor microenvironment. (Uppsala: Uppsala University).

40. Kang T, Jones TM, Naddell C, Bacanamwo M, Calvert JW, Thompson WE, Bond VC, Chen YE, Liu D. Adipose-Derived Stem Cells Induce Angiogenesis via Microvesicle Transport of miRNA-31. Stem Cells Transl Med. 2016; 5: 440-50. doi: sctm.2015-0177 [pii] https://doi.org/10.5966/sctm.2015-0177.

41. Pan Q, He C, Liu H, Liao X, Dai B, Chen Y, Yang Y, Zhao B, Bihl J, Ma X. Microvascular endothelial cells-derived microvesicles imply in ischemic stroke by modulating astrocyte and blood brain barrier function and cerebral blood flow. Mol Brain. 2016; 9: 63. https://doi.org/10.1186/ s13041-016-0243-1 10.1186/s13041-016-0243-1 [pii].

42. Cantaluppi V, Gatti S, Medica D, Figliolini F, Bruno S, Deregibus MC, Sordi A, Biancone L, Tetta C, Camussi G. Microvesicles derived from endothelial progenitor cells protect the kidney from ischemia-reperfusion injury by microRNA-dependent reprogramming of resident renal cells. Kidney Int. 2012; 82: 412-27. doi: S00852538(15)55556-7 [pii] https://doi.org/10.1038/ki.2012.105.

43. Salafutdinov I. I. SAK, Yalvach M. E., Kudryashova N. V., Lagarkova M. A., Shutova M. V., Kiselev S. P., Masgutov R. F., Zhdanov R. I., Kiyasov A. L., Islamov P. P., Rizvanov A. A. Effect of simultaneous expression of various usoforms of vascular endothelial growth factor VEGF and fibroblast growth factor FGF2 on proliferation of human umbilical cord blood cells HUVEC. Cellular Transplantation and Tissue Engineering. 2010; 5: 62-7. 